\title{
Spontaneous Spinal Epidural Hematoma Mimicking Stroke and Its Outcome post Intravenous Thrombolysis
}

\author{
Cheuk Ling Charing Szeto Kwok Fai Hui \\ Department of Medicine and Geriatrics, United Christian Hospital, Kwun Tong, Hong Kong SAR
}

\section{Keywords}

Stroke $\cdot$ Thrombolytic $\cdot$ tPA $\cdot$ Stroke mimics $\cdot$ Spinal epidural hematoma

\begin{abstract}
Background and Purpose: Spontaneous spinal epidural hematoma (SSEH) is a rare neurological emergency. Its presentation, depending on location of hematoma, could mimic stroke. While intravenous thrombolysis (IVT) is recommended to commence as early as possible in case of acute ischemic stroke, it is likely that it could be given to SSEH patients. We aimed to examine the prevalence, outcome, and prognosis of such patients. Methods: We have retrospectively screened all patients given IVT from January 2008 to March 2021 admitted to United Christian Hospital, a tertiary hospital in Hong Kong. We reviewed the final diagnosis of all patients and included cases diagnosed with SSEH. Their clinical and radiological features, treatment, and outcome were analyzed. We further performed a literature review to search for all cases with SSEH given IVT and review their clinical features and outcome. Results: Out of a total of 940 patients over the 12-year span, 2 patients were diagnosed with SSEH, accounting for $0.21 \%$ of cases. From our literature search, to
\end{abstract}

date, there are only 10 cases that had been reported from 5 case reports where IVT was given to SSEH patients. Of the 12 cases, all presented with hemiparesis and 9 with pain. Of those with neck pain, 3 with initial computed tomography angiogram done showed SSEH which was missed initially. Eight were treated surgically and 4 conservatively. All recovered with no major disability. Conclusions: Though a rare disease, awareness toward SSEH presenting as stroke mimic should be raised.

() 2021 S. Karger AG, Basel

\section{Introduction}

Intravenous thrombolysis (IVT) is the mainstay of treatment for acute ischemic stroke (AIS). The limited time frame and aim to shorten door-to-needle time prompt clinicians to make decision on treatment instantaneously, rendering insufficient time for observation of clinical progressions to confirm the diagnosis.

Most of the time, it was safe with small bleeding risk even when IVT was given to stroke mimics like migraine and Bell's palsy (risk of symptomatic intracerebral hemorrhage (sICH) compared with patients with karger@karger.com www.karger.com/ced (c) 2021 S. Karger AG, Basel

Karger!"
Correspondence to:

Cheuk Ling Charing Szeto, charingszeto@gmail.com 


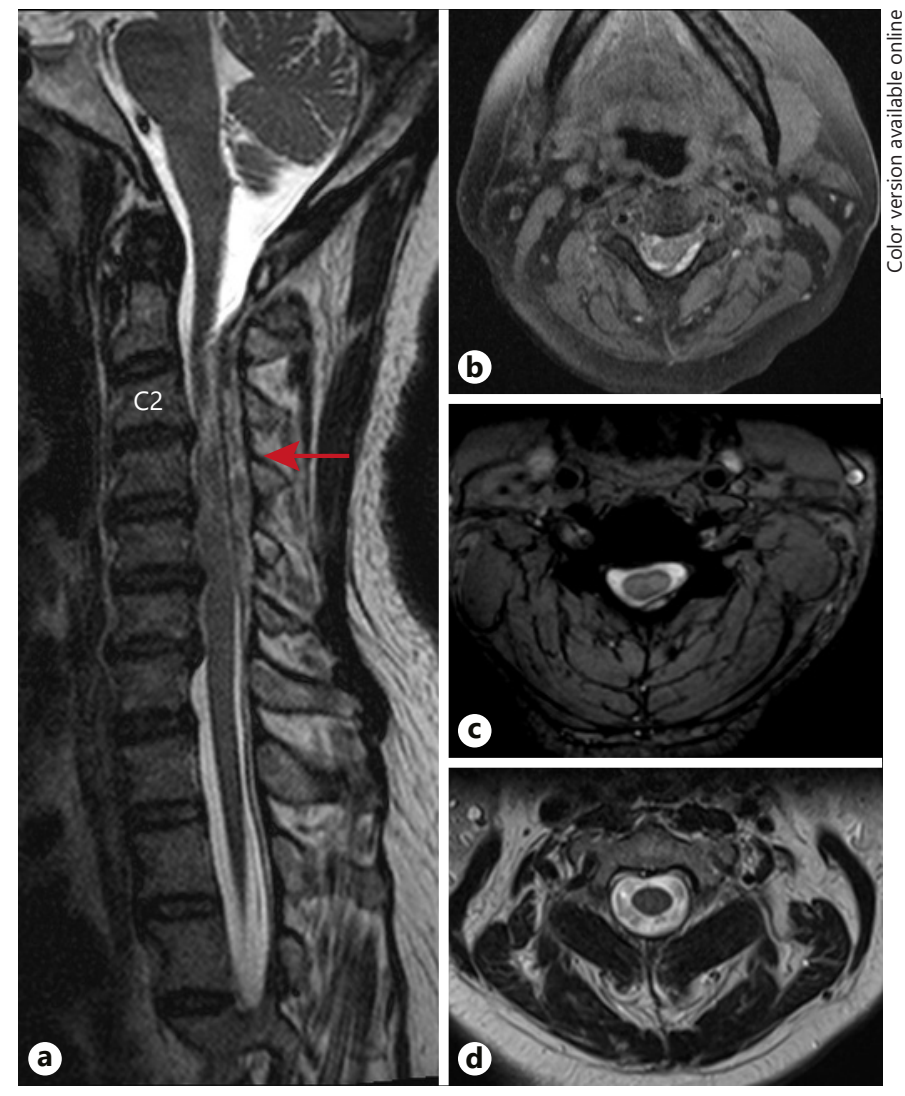

Fig. 1. MRI cervical spine 1 week, 2 weeks, and 3 months from onset. a, b Axial T1-weighted and sagittal T2-weighted MRI showing hyperintense signal in the left posterior epidural space compatible with epidural hematoma (red arrow). c Follow-up MRI at 2 weeks from onset showing significant reduction in hematoma size. $\mathbf{d}$ At 3 months from onset, the hematoma completely subsided. MRI, magnetic resonance imaging.

AIS was significantly lower with risk ratio $=0.33$ ) [1]. It was further reassuring that even for AIS attributing to intracranial dissection, IVT was reported to be relatively safe [2].

However, it had come to our recognition that for a hemorrhagic condition - spontaneous spinal epidural hematoma (SSEH), IVT may be potentially harmful when given inadvertently. Yet it was at the same time difficult to differentiate from true AIS, especially for cervical SSEH.

SSEH is a rare neurological emergency with incidence estimated to be 0.1 patients per 100,000 patients per year [3]. It is defined to be SSEH if blood accumulates in the spinal epidural space spontaneously without an obvious traumatic or iatrogenic cause, as proposed by Lonjon et al. [4]. It was commonly presented with acute neck or
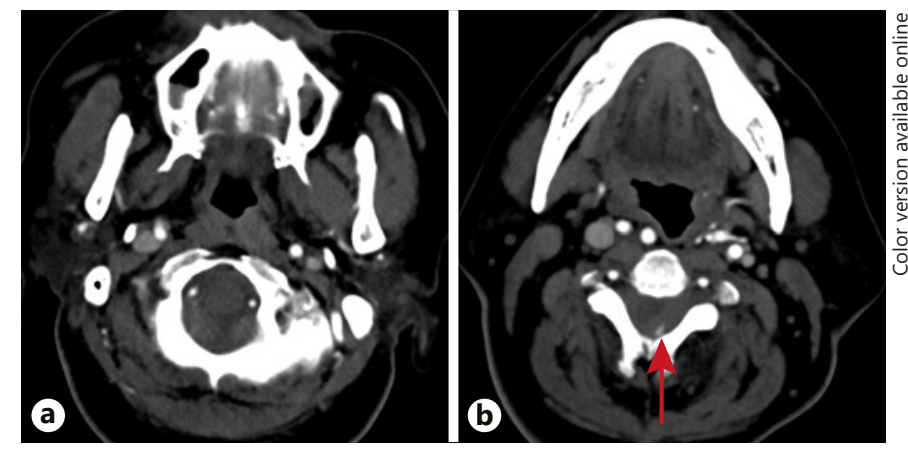

Fig. 2. CT angiogram at presentation. a Contrast CT angiogram showing no carotid or vertebral artery dissection, stenosis, or occlusion. b A tiny hyperdense focus at the posterior epidural space in the $\mathrm{C} 2 / 3$ level. CT, computed tomography.

back pain, followed by neurological symptoms ranging from pure sensory symptoms to a full-blown cord compression syndrome. Yet of note, $15 \%$ was painless and 3 out of 13 patients in a case series presented with hemiparesis [5], which would be potentially mistaken as AIS when presented hyper-acutely.

The outcome and management of SSEH after administration of IVT were unclear. The purpose of this study was to enhance our understanding toward SSEH and its outcome and potential treatment options through review of cases.

\section{Methods}

We had identified all patients admitted to United Christian Hospital, a tertiary hospital in Hong Kong, from 1 January 2008 to 31 March 2021 for suspected AIS with IVT given. We aimed to identify those with SSEH as stroke mimics.

A literature search was performed using PubMed, Ovid, and Google Scholar to identify cases of SSEH who had been given IVT. The inclusion criterion for literature review was SSEH given IVT. Cases that had spinal epidural hematoma diagnosed as a consequence of IVT were excluded. The definition of SSEH was adapted as mentioned earlier. We reviewed their demographical characteristics, clinical features, radiological findings, treatment, and outcome. This study was approved by KEC Ethics Committee.

\section{Results}

From January 2008 to March 2021, a total of 940 patients were treated with IVT. Around half were male, with a median age of 74 (range $=21-97$ ) years. Among them, 2 were diagnosed with SSEH, accounting for $0.21 \%$ of all IVT-treated cases. 
Table 1. Characteristics of all patients with SSEH treated with IVT [6-9, 12-17]

\begin{tabular}{|c|c|c|c|c|c|c|c|c|c|c|c|}
\hline No. & Source & Country & Sex & $\begin{array}{l}\text { Age, } \\
\text { years }\end{array}$ & $\begin{array}{l}\text { Pain on } \\
\text { presentation }\end{array}$ & $\begin{array}{l}\text { Neurological deficit on } \\
\text { presentation }\end{array}$ & $\begin{array}{l}\text { Modality of } \\
\text { diagnosis }\end{array}$ & $\begin{array}{l}\text { Location of } \\
\text { hematoma }\end{array}$ & $\begin{array}{l}\text { Time to } \\
\text { diagnosis }\end{array}$ & Treatment & $\begin{array}{l}\text { Out- } \\
\text { come }\end{array}$ \\
\hline 1 & Current article & Hong Kong & $\mathrm{F}$ & 61 & Yes & $\begin{array}{l}\text { Neck pain } \\
\text { L hemiparesis }\end{array}$ & $\mathrm{CT} / \mathrm{MRI}$ & $\begin{array}{l}\text { Posterior } \\
\text { L C2-T3 }\end{array}$ & 6 day & Conservative & MD \\
\hline 2 & Current article & Hong Kong & M & 58 & No & $\begin{array}{l}\text { L hemiparesis and } \\
\text { numbness }\end{array}$ & MRI & $\begin{array}{l}\text { Posterior } \\
\text { L C4-7 }\end{array}$ & $19 \mathrm{~h}$ & Surgical & GR \\
\hline 4 & $\begin{array}{l}\text { Watanabe } \\
\text { et al. [8] }\end{array}$ & Japan & $\mathrm{F}$ & 65 & Yes & $\begin{array}{l}\text { Shoulder and back pain } \\
\text { R hemiparesis }\end{array}$ & $\mathrm{CT} / \mathrm{MRI}$ & $\begin{array}{l}\text { Posterior } \\
\text { R C3-6 }\end{array}$ & $5 \mathrm{~h}$ & Surgical & $\mathrm{GR}$ \\
\hline 5 & Lee [12] & Korea & $\mathrm{F}$ & 66 & Yes & $\begin{array}{l}\text { Neck pain } \\
\text { L Hemiparesis }\end{array}$ & $\mathrm{CT}$ & $\begin{array}{l}\text { Posterior } \\
\text { C3-4 }\end{array}$ & $?$ & Surgical & MD \\
\hline 8 & $\begin{array}{l}\text { Morimoto } \\
\text { et al. [14] }\end{array}$ & Japan & M & 71 & Yes & $\begin{array}{l}\text { Neck pain } \\
\text { L hemiparesis }\end{array}$ & MRI & $\begin{array}{l}\text { Posterior } \\
\text { L C4-6 }\end{array}$ & $24 \mathrm{~h}$ & Surgical & MD \\
\hline 9 & Hara et al. [15] & Japan & M & 68 & Yes & $\begin{array}{l}\text { Neck and back pain } \\
\text { R paresthesia, } \\
\text { hemiparesis, } \\
\text { Horner syndrome }\end{array}$ & MRI & $\begin{array}{l}\text { Posterior } \\
L>R C 1-7\end{array}$ & $93 \mathrm{~h}$ & Conservative & GR \\
\hline 10 & $\begin{array}{l}\text { Yurter and } \\
\text { Kaloostian [9] }\end{array}$ & USA & $\mathrm{F}$ & 69 & No & L hemiparesis & MRI & $\mathrm{C} 1-\mathrm{T} 1$ & $?$ & Surgical & $\mathrm{GR}$ \\
\hline 11 & Son et al. [16] & Korea & M & 63 & Yes & $\begin{array}{l}\text { Neck and shoulder pain } \\
\text { L hemiparesis }\end{array}$ & MRI & $\begin{array}{l}\text { Posterior } \\
\text { L C4-T2 }\end{array}$ & $3 \mathrm{~h} 30 \mathrm{mo}$ & Surgical & MD \\
\hline
\end{tabular}

F, female; M, male; L, left; R, right; C, cervical spine; T, thoracic spine; GR, good recovery (defined as no neurological deficit or no significant disability); MD, moderately disabled (defined as incomplete motor return and required aids in walking); SD, severely disabled (defined as bedridden); D, dead; SSEH, spontaneous spinal epidural hematoma; IVT, intravenous thrombolysis; $\mathrm{CT}$, computed tomography; MRI, magnetic resonance imaging.

\section{Details of Both Cases}

Patient 1

A 61-year-old woman with good past health presented with sudden-onset neck pain and left hemiparesis. Other neurological examinations were normal. There was no trauma or neck manipulation. Computed tomography (CT) of the brain was unremarkable, and CT angiogram showed no major artery dissection.

IVT was given with power improved from grade 0 to $3 / 5$, but neck pain persisted. Subsequent MRI and MRA of the brain were unremarkable, while MRI of the cervical spine showed epidural hematoma from C2 to T1 (Fig. 1). Retrospective review of initial CT angiogram noted tiny
SSEH at C2 (Fig. 2). MRA of the spine showed no underlying arteriovenous fistula or arteriovenous malformation.

She was managed conservatively. MRI showed resolution of hematoma with improved mobility to walking with aid and managed daily activities at 3-month followup.

\section{Patient 2}

A 58-year-old man with good past health presented with sudden onset left-sided numbness and weakness. He did not complain of any neck pain or trauma, and neurological examination was unremarkable, except for 
left hemiparesis with grade $0 / 5$ for the upper limb and $4 / 5$ for the lower limb. IVT was given after brain CT was revealed normal. The patient progressed to become tetraplegic with acute retention of urine upon observation after an hour of thrombolysis. Urgent whole spine MRI showed epidural hematoma at C4-7 level. Fresh frozen plasma, platelet concentrates, and cryoprecipitate were given, and urgent decompressive surgery was carried out. The patient had good recovery with power back to full 4 weeks after surgery. To further understand SSEH patients given IVT, a literature search was performed, and a total of 10 cases were extracted from 5 eligible case reports [6-10]. Along with the 2 cases we presented, all 12 cases are summarized in Table 1 . Presentation, investigation modality, and outcome were listed. Outcome was defined as the maximal resolution of neurological deficit.

All cases presented with hemiparesis, and the location of SSEH was at the cervical region. Pain was present in most of the cases (9 in 12). Of note, in cases 1,3 , and 4 where neck pain was present, and urgent head and neck CT angiogram was performed to rule out dissection before IVT was given. In all 3 cases, retrospective review of the initial CT film revealed epidural hematoma at the cervical region.

Of the 12 cases, 8 were treated surgically and 4 were treated conservatively. Of those treated surgically, 6 out of 8 had good recovery, while those treated conservatively, 3 out of 4 had good recovery. None of the cases suffered from major adverse events from IVT, like symptomatic intracerebral hemorrhage or other major bleeding.

\section{Discussion}

This is a single-center retrospective study spanning over 12 years. In this long period of time, the occurrence of stroke mimics was relatively low. SSEH remains a rare cause, with only 2 cases seen, accounting for $0.21 \%$ of all IVT-treated cases.

This was to date the first case review on SSEH as stroke mimics with IVT given. Extensive literature searches only revealed a total of 10 cases with SSEH given IVT erroneously.

It was of note that in cases presented with neck pain, 3 of them had head and neck CT angiogram performed, and the diagnosis of spinal epidural hematoma was missed. This illustrated despite a window for diagnosis of SSEH before the administration IVT, it was missed due to lack of awareness to the condition.
The largest literature review on SSEH to date recruited 65 cases from 12 studies [11]. Up to $50 \%$ of cases did not fully recover and continued to have some level of sensorimotor deficiency. Disease-related mortality was up to $5.7 \%$.

Overall, compared with general SSEH cases in the review mentioned, the outcome of all 12 cases was not particularly worsened due to IVT. On contrary, it was relatively favorable, with none severely disabled or died. Overall, $66.7 \%$ ( 8 out of 12 ) had full neurological recovery or just mild deficit without significant disability. It showed no obvious preference toward surgical or conservative treatment. In the literature review, the degree of preoperative neural deficit is the major prognostic factor and conservative management has been proven effective, although it was feasible only if spontaneous recovery is manifested. This rationale appeared to hold true for SSEH patients, despite given IVT.

With the increasing use of IVT and mechanical thrombectomy, it is believed we would encounter more cases with SSEH presenting as stroke mimics in the future. This warrants the attention of physicians to be cautious and consider the possibility of SSEH before commencing IVT.

There are a few limitations in this study. First, this is a retrospective study and patients' follow-up timing was different depending on decisions by treating physicians. Second, not all patients underwent spinal imaging; hence, it was possible that spinal pathologies were underdiagnosed. Third, due to rarity of the disease, the sample size was small.

\section{Conclusion}

SSEH is a rare stroke mimic accounting for $0.21 \%$ cases in our 12-year cohort receiving IVT. Awareness toward SSEH should be enhanced to prevent erroneous administration of IVT and delay in treatment.

\section{Statement of Ethics}

This study was approved by KEC Ethics Committee (Reference No.: KC/KE-21-0096/ER-1). Written informed consent was obtained from the patients for publication for this case report and any accompanying images.

\section{Conflict of Interest Statement}

The authors have no conflicts of interest to declare. 


\section{Funding Sources}

There is no funding involved.

\section{Author Contributions}

Dr. Szeto was responsible for case collection, reviewing cases from literature, drafting, and writing the manuscript. Dr. Hui was responsible for supervising and providing critical feedback for the manuscript.

\section{References}

1 Tsivgoulis G, Zand R, Katsanos AH, Goyal N, Uchino K, Chang J, et al. Safety of intravenous thrombolysis in stroke mimics: prospective 5 -year study and comprehensive meta-analysis. Stroke. 2015;46(5):1281-7.

2 Bernardo F, Nannoni S, Strambo D, Bartolini B, Michel P, Sirimarco G. Intravenous thrombolysis in acute ischemic stroke due to intracranial artery dissection: a single-center case series and a review of literature. J Thromb Thrombolysis. 2019;48(4):679-84.

3 Holtås S, Heiling M, Lönntoft M. Spontaneous spinal epidural hematoma: findings at MR imaging and clinical correlation. Radiology. 1996;199(2):409-13.

4 Lonjon MM, Paquis P, Chanalet S, Grellier P. Nontraumatic spinal epidural hematoma: report of four cases and review of the literature. Neurosurgery. 1997;41(2):483-7.

5 González AM, Cuelloa JP, Cruza PMR, Mohedanoa AMI, Rubioa RD, Delgado FR, et al. Spontaneous spinal epidural haematoma: a retrospective study of a series of 13 cases. Neurología. 2015;30(7):393-400.

6 Patel R, Kumar A, Nishizawa K, Kumar N. Hemiparesis in spontaneous spinal epidural haematoma: a potential stroke imitator. BM] Case Rep. 2018;2018. bcr-2017.

\section{Data Availability Statement}

All data generated or analyzed during this study are included in this article. Further inquiries can be directed to the corresponding author.
7 Rahangdale R, Coburn J, Streib C. Spontaneous cervical epidural hematoma mimicking acute ischemic stroke. Neurology. 2020; 95(11):496-7.

8 Watanabe M, Abe E, Sakamoto K, Horikoshi $\mathrm{K}$, Ueno H, Nakao Y, et al. Analysis of a spontaneous spinal epidural hematoma mimicking cerebral infarction: a case report and review of the literatures. no shinkei geka. Neurol Surg. 2020;48(8):683-90.

9 Yurter A, Kaloostian PE. Spontaneous cervical epidural hematoma mimicking stroke: a new perspective on diagnosis and treatment. Open J Mod Neurosurg. 2013;2013.

10 Lee C-H, Kwun K-H, Jung K-H. Spontaneous spinal epidural hematoma treated with tissue plasminogen activator mimicking ischemic stroke. Interdiscip Neurosurg. 2020;19: 100569.

11 Raasck K, Habis AA, Aoude A, Simões L, Barros F, Reindl R, et al. Spontaneous spinal epidural hematoma management: a case series and literature review. Spinal Cord Ser Cases. 2017;3(1):16043-6.
12 Lee C-H, Kwun K-H, Jung K-H. Spontaneous spinal epidural hematoma treated with tissue plasminogen activator mimicking ischemic stroke. Interdiscip Neurosurg. 2020;19: 100569.

13 Shimada E, Tomari S, et al. A case of cervical spinal epidural hematoma diagnosed as acute stroke and given thrombolytics. Orthop Traumatol. 2018;67(3):519-22.

14 Morimoto T, Yoshihara T, Yakushiji Y, et al. Worsening cervical epidural hematoma after tissue plasminogen activator administration for stroke like symptoms. Spine. 2016;41: E437-440.

15 Hara N, Otonari T, Nishihara N, Ota T, Kuriyama M. Clinical manifestations of 16 patients with spontaneous spinal epidural hematoma - Stroke mimic and pitfalls for diagnosis. Clin Neurol. 2014;54:395-402.

16 Son S, Kang DH, Choi DS, Kim SK, Lim BH, Choi NC. A case of spontaneous spinal epidural hematoma mimicking a stroke. Neurologist. 2012;18:41-3.

17 Okada E, Matsumoto M, Watanabe K, et al. A case of spontaneous spinal epidural hematoma that mimicked acute cerebral ischemic stroke and was treated by a recombinant tissue-type plasminogen activator. Neurosurg Q. 2012;22:99-101. 